\title{
AS INFLUÊNCIAS DE VOZES APRECIATIVAS NA NOSSA CONSTITUIÇÃO IDENTITÁRIA
}

THE INFLUENCE OF APPRECIATIVE VOICES ON OUR IDENTITY BUILDING

RESUMO: Tendo como base alguns pressupostos do construcionismo social, ideias da abordagem colaborativa e dialógica, das práticas narrativas e da investigação apreciativa, apresento um caso clínico que ilustra conceitos das terapias pós-modernas através de conversações transformadoras que emergem de trocas dialógicas entre o terapeuta e o cliente. Neste artigo compartilho essa experiência clínica que amplia nossa compreensão sobre a concepção de self dialógico, a constituição polivocal de nossa identidade, considerando sermos construídos através dos relacionamentos dos quais fazemos parte e de reconhe-cermos as vozes de pessoas significativas de nossas vidas para restaurarmos uma versão mais apreciati-va de nós mesmos.

PALAVRAS-CHAVE: Self narrativo; Identidade; Pós-modernidade; Diálogo; Colaboração e terapia narrativa..
ABSTRACT: Alongside the prerequisites of Social constructionism, collaborative and dialogical approaches, narra-tive therapy and appreciative inquiry, I present a clinical case that exemplifies post-modern therapies concepts through a process of transforming talk that occurs from dialogical exchanges between the therapist and the client. In this article I share this clinical experience that increases our comprehension of dialogical self's conception, the polyvocal composition of our identity, contemplating that we are built through our relationships and the meaningful people's voices recognition to rebuild an apprecia-tive version of ourselves.

KEYWORDS: Narrative Self; Identity; Post-modernity; Dialogue; Collaborative and narrative therapy.
NINA VASCONCELOS GUIMARÃES

Instituto Humanitas, Salvador/BA, Brasil

\section{FUNDAMENTOS DE UMA PRÁTICA CLÍNICA PÓS-MODERNA}

As nossas tradições terapêuticas merecem uma revisão que nos permita questionar e restaurar os relacionamentos com nossos clientes, a forma habitual com que pensamos sobre e nos dirigimos a eles. Estamos diante do desafio de polemizar a estrutura e a linguagem de um processo terapêutico, de deslizar da verticalidade à horizontalidade na relação terapêutica, na esperança de que nossas práticas funcionem mais apropriadamente às conformidades contemporâneas.

Muitos de nós parecem recorrer à terapia para revisar conceitos, abandonar hábitos arcaicos descontextualizados e buscar um crescimento mais profundo de si mesmo; assim, por esta razão, as nossas atuações terapêuticas merecem revisão sempre que possível. Não podemos continuar adotando a visão modernista de $e x$ pertise, que defende uma posição neutra e objetiva sobre os fenômenos dos quais fazemos parte, mas, ao invés disso, parece prudente adotarmos uma atitude mais colaborativa, horizontal e corresponsável, típica das práticas terapêuticas coletivas que prezam por um compartilhamento (Gergen, 2017, 2018; Gergen \& Warhus,

Recebido em: 08/05/2018 Aprovado em: 25/09/2018 
2001; Grandesso, 2018; McNamee, 2018; McNamee \& Gergen, 1998).

A precisão do discurso científico deixa de ser o único baluarte considerável (Gergen \& Gergen, 2010). Os discursos construcionistas rompem com as convenções tradicionais reconhecidas como únicas e verdadeiras, e propõem uma revisão crítica que não adota mais uma verdade única e singular, mas sim um amplo espectro de possibilidades, um convite infinito de alternativas onde podemos transformar um problema em uma possibilidade, a depender do uso linguístico com que nos referimos aos fenômenos. Assim, "o que é real deriva de acordos entre comunidades de pessoas, as afirmações da verdade devem se encontrar no âmbito dessas relações" (Gergen \& Gergen, 2010, p. 29).

Uma investigação terapêutica baseada nos princípios pós-modernos pressupõe processos discursivos e relacionais de produção de sentido focalizados no modo como as pessoas constroem, numa ação conjunta e corporificada de uso da linguagem, determinadas realidades conversacionais (Rasera \& Guanaes, 2010).

Os momentos denominados marcantes em relacionamentos humanos, em especial, no contexto privilegiado da terapia, oportunizam que algo, nunca antes dito, encontre sua forma de expressão. Quando isso ocorre estamos diante da poética social. A construção local de um conhecimento novo e significativo torna-se possível quando abandonamos qualquer saber a priori, geralmente associado à figura de um terapeuta expert que encaixaria o cliente em um critério classificatório, reduzindo suas possibilidades de vida. A poética social devolve-lhe o senso de autoria, descortinando um multiverso a ser explorado (Grandesso, 2018; Rasera \& Guanaes, 2010).
Grandesso (2000) defende a ideia de que para que haja a possibilidade de reconstrução de significados, seja necessária a quebra de sentido de acontecimentos que não se encaixam nas narrativas emergentes, transformando o familiar em exótico. Do mesmo modo, Rasera e Guanaes (2010), discutindo e citando Shotter e Katz (1999), falam sobre as possibilidades de significação que emergem a partir da prática da poética social, defendendo que uma terapia de base conversacional tem o objetivo de favorecer um entendimento que dá visibilidade a algo já presente no relato do cliente, mas que ainda não tinha se destacado como descrição predominante ou encontrado um espaço de expressão em outros contextos conversacionais.

Novos mundos tornam-se possíveis na medida em que a mudança vai se operando. No cenário terapêutico a mudança é distintamente considerada dentre as perspectivas moderna e pós-moderna. Na primeira delas, os critérios diagnósticos e os sintomas devem ser considerados e a evolução terapêutica segue um critério de remoção de sintoma e transformação de comportamentos ditos problemáticos para outros mais "aceitáveis" socialmente. Já na perspectiva pós-moderna, baseada em pressupostos construcionists sociais, o processo de mudança não segue a lógica linear de o indivíduo sair de um quadro para o outro de evolução, mas, sim, favorece ao sujeito narrativas conversacionais transformadoras que ampliem suas possibilidades de existência, que não estejam reduzidas a um único olhar ou voz, mas que sejam favorecidas pela multivocalidade. Como afirma Guanaes (2006), importa às terapias com foco na conversação buscar os sentidos de mudança que mais se aproximem da narrativa de problema 
apresentada pelo cliente, e que possam ampliar suas possibilidades de vida e de relacionamento.

O encontro dialógico é o cenário privilegiado para a emergência de novos significados em nossas vidas. É uma oportunidade única para os interlocutores construírem conjuntamente uma gama de novos sentidos para suas experiências. O diálogo é uma atividade colaborativa e relacional onde a qualidade da relação assume importância vital. A presunção precedente de antevermos o que o outro deseja nos falar é substituída por uma indagação compartilhada em que a voz do outro é enaltecida e respeitada, considerando que podemos apenas nos aproximar do significado do relato que ele nos apresenta (Anderson, 2017). Grandesso (2018) retoma as ideias de Bakhtin que inspiraram Shotter sobre a distinção de um pensamento withness em detrimento de um pensamento aboutness. Diz a autora:

Enquanto uma relação aboutness apresenta-se como monológica, tendo uma voz privilegiada que versa sobre uma determinada situação, a relação withness é eminentemente dialógica, convidando os envolvidos na relação para uma ação conjunta de investigação compartilhada. O que resulta desta relação é de autoria coletiva, uma vez que a relação withness cria tanto o seu contexto como o conteúdo e processo. (p. 156)

Pautada nos pressupostos construcionistas sociais e nas práticas colaborativas e dialógicas, os diálogos só ocorrem mediante as ações suplementares de seus integrantes, que complementam e se reportam àquilo que é dito nas conversações. Portanto, nossas ações devem ser conside- radas como construções conjuntas que permitem a emergência de novos significados. Somos parceiros conversacionais, desfrutando de um senso de mutualidade que inclui o respeito, o interesse e a curiosidade genuína que se traduz em uma postura filosófica denominada de não saber. Esta posição de não saber evita um posicionamento prematuro e opressor de compreensão do dilema, nos convida a adotar uma curiosidade genuína e nos envolve em uma busca horizontal, igualitária e recíproca de compreensão (Anderson, 2011). Grandesso (2018) complementa essa ideia se referindo a uma entrevista colaborativa como uma prática dialógica que segue diferentes estradas, sem um roteiro apriorístico, onde o terapeuta transita pela incerteza enquanto aliada de sua curiosidade genuína, mantendo sua escuta eminentemente aberta.

Ainda de acordo com a ótica construcionista, a nossa identidade é composta pelo olhar do outro, somos seres constituídos em relação. O nosso self é fluido e sujeito a mudanças, a depender das interlocuções que estabelecemos durante a vida. A concepção moderna de um self essencialista, fixo e permanente é descartada e considerada uma ilusão. Em sua célebre frase, o relacionamento é a morada do conhecimento, Gergen propõe que, as verdades e as identidades, por serem o produto de relacionamentos humanos, não sejam fixas, nem imutáveis, mas sim flexíveis e temporárias.

Dentro da perspectiva de que nossas identidades são fluidas e constantemente sujeitas à adaptações, fazemos referência ao conceito dialógico e relacional de self de Harlene Anderson (2011). De acordo com a autora, nossas identidades e aquelas que atribuímos aos demais são relacionais e se constroem no diálogo e na conversação

$$
\text { Nira }
$$


(Gergen, 2016; 2017). Falamos, pensamos e atuamos com uma multiplicidade de vozes que habita em cada um de nós. Toda narrativa que construímos de nós mesmos pode ser renarrada e transformada, ofertando uma nova forma e um novo lugar ao sujeito. A construção dialógica do self permite descartar a noção de essência do indivíduo e considerar uma multiplicidade de noções de selves que emergem de dentro do próprio diálogo em curso - um self como um constructo sócio-cultural singular dos discursos mais amplos e locais em que ocorre.

A noção de self narrativo amplia as perspectivas de mudanças no cliente, tanto quanto algumas práticas narrativas pós-modernas de White e Epston (1990), particularmente duas delas, a de re-autoria e a de re-associação. Esses autores contemplam a ideia de que nenhuma história, em si, condensa os múltiplos significados que ela própria constitui, o que faz com que o terapeuta deva permanecer atento às contradições presentes no relato de seu cliente, às lacunas que vêm a ser preenchidas por acontecimentos extraordinários (Galvão \& Guimarães, 2014).

A terapia narrativa permite ao terapeuta compor uma visão mais otimista e competente do cliente. Através de cenas recuperadas em diálogos terapêuticos, é possível escavar momentos extraordinários dele, acompanhados de personagens significativos de sua vida que, em algum momento, podem emprestar uma versão menos saturada e mais alternativa de si. Cada nova história re-narrada em terapia, contemplada pelo olhar apreciativo de nossos interlocutores, aqueles com os quais nos relacionamos ou os demais que permanecem internalizados em nós, permite a composição de uma história subordinada forte o suficiente para aplacar a história dominante.
De acordo com esta proposta terapêutica, a vida das pessoas é multi-historiada por uma história dominante/oficial, que apresenta parte das experiências vividas que acabam por qualificar e constituir o sujeito, e por uma história subordinada/secundária, formada por uma variedade de narrativas alternativas que incluem as experiências negligenciadas pela história dominante. A busca da história subordinada permite ao sujeito adentrar outros territórios de sua identidade, explorando recursos, habilidades e capacidades até então ocultas e adormecidas (Palma, 2008).

A prática narrativa de re-autoria surge de nossas conversações e favorece uma gama de competências, talentos e habilidades à vida de nosso cliente, restaurando uma imagem denegrida em uma percepção mais otimista e promissora, recuperando o seu senso de autoria. Aos poucos as conversações terapêuticas podem resgatar personagens importantes de nossas vidas que nos trazem uma visão mais apreciativa de nós e, assim, os diálogos nos conduzem a uma outra prática narrativa - a re-associação (re-membering).

Esta prática terapêutica de re-associação utilizada por Michael White sofreu influência direta dos trabalhos desenvolvidos pela antropóloga Bárbara Meyerhoff, com grupos de minoria, chegando a considerar a importância do termo re-membering (re-membrar, re-associar), ressaltando o significado de recuperarmos pessoas importantes em algum momento de nossas histórias de vida que permaneceram "apagadas".

Estas pessoas que apresentam status diferentes em determinados momentos de nossa existência são os sócios ou membros do que se denomina clube da vida. O pensamento subjacente a esta 
prática de re-associação se baseia na concepção pós-estruturalista de que nossas identidades são tecidas pelos relacionamentos que estabelecemos com outras pessoas.

Ressaltar pessoas importantes em alguns momentos de nossas histórias de vida que permaneceram "apagadas" consiste em uma oportunidade única e trazê-las à tona nos remete ao quanto foram importantes na construção de nossas identidades e, consequentemente, influenciaram na forma como nos percebemos.

As conversações de re-membramento tornam-se úteis sempre que o cliente se refere a alguém importante de seu passado, ou quando sustenta uma visão negativa de si mesmo. São conversações que funcionam como antídoto pois, ao se sentirem desanimados e desesperançosos na vida, a prática de re-membramento proporciona a ampliação ou resgate de "sócios" significativos que promovam imagens adversas mais positivas do que aquelas saturadas carregadas pelo cliente.

O caso a ser aqui apresentado mostra-se particularmente instigante para o estudo das conversações terapêuticas transformadoras pautadas em alguns pressupostos do construcionismo social, em duas práticas narrativas, a de re-autoria e re-associação de Michael White e David Epston (1990), na Abordagem Colaborativa de Harlene Anderson (2011) e na Investigação Apreciativa de Cooperrider e Whitney (2005). A forma construtiva como o diálogo terapêutico se estabeleceu dentro de uma horizontalidade e uma curiosidade favoreceu uma mudança na imagem que a cliente sustentava de si a partir do resgate de pessoas significativas de sua vida que compuseram uma imagem mais apreciativa dela. Todas essas abordagens, cada uma com sua singularidade, encontram convergências quanto à ênfase nos processos relacionais, no enaltecimento da linguagem e na postura terapêutica voltada à horizontalidade, à coconstrução e ao interesse pelo significado (Rasera \& Guanaes, 2010).

Particularmente, me guiei pelas ideias construcionistas e fundamentei nossas conversações mantendo (a) o foco no significado; (b) em como as pessoas se constroem em relacionamentos e nos significados que orientam suas vidas; (c) na postura coconstrutora do terapeuta, abandonando o papel de especialista e criando conversações que sugerem novos sentidos para a vida do cliente; (d) na ênfase polivocal em oposição à ideia de uma única e verdadeira definição do real; e (e) na visão de um self unificado que promove uma multiplicidade de formas de descrever um problema e na pluralidade de selves que nos habita nos vários relacionamentos que construímos.

Para complementar as reflexões, faço referência a algumas posturas de práticas colaborativas e dialógicas de Harlene Anderson (2017) que elevam o papel do diálogo, o estar com numa indagação compartilhada e a postura terapêutica do não saber, de uma curiosidade genuína frente ao relato do cliente, permitindo a emergência de novos significados para a sua vida.

Utilizo duas práticas narrativas propostas por White e Epston (1990); refiro-me primeiramente à prática da re-autoria, onde exploro histórias alternativas e estocadas da vida da cliente e, depois, complemento com a prática de re-associação, resgatando pessoas significativas de sua vida que participaram de sua constituição identitária e trouxeram um olhar mais promissor para sua imagem. Seguindo com uma postura pós-moderna, faço 
referência aos seguintes pressupostos da Investigação Apreciativa (Cooperrider \& Whitney, 2005): (a) de que as realidades surgem de um certo momento, a partir da linguagem que utilizamos ao valorizarmos as diferenças e de (b) recuperar experiências do passado que permitem que as pessoas se sintam mais confortáveis e confiantes sobre os seus futuros (Mofarrej, Costa, \& Pacheco, 2017).

Considerando que uma mesma pessoa pode apresentar várias narrativas ao longo de um processo terapêutico, selecionei recortes de uma sessão específica individual que durou um ano e meio, com intervalos quinzenais no meu consultório particular. A sessão de onde foram extraídos os fragmentos a serem analisados foi audiogravada e ocorreu na sala de espelho unidirecional com equipe terapêutica durante uma aula do curso de formação no Instituto Humanitas de Pesquisa e Intervenção em Sistemas Humanos, em Salvador, Bahia. A transcrição foi realizada posteriormente pela terapeuta, para que algumas metáforas trazidas pela cliente pudessem ser literalmente recuperadas e a análise correlacionada a algumas práticas pós-modernas que pudessem ser mais bem estruturadas nesta produção científica. Este trabalho respeitou todos os procedimentos éticos, contando com a leitura e autorização da pessoa atendida para a publicação deste artigo. A fim de preservar sua identidade, utilizarei um nome fictício ao longo deste trabalho: Malu.

O objetivo dessa produção é refletir sobre o impacto de algumas conversações terapêuticas transformadoras que ocorreram na vida da cliente, especificamente, sobre a premissa construcionista de que somos seres constituídos pelo olhar do outro, cuja imagem identitária é moldada por aqueles que nos cercam, admitindo, dessa forma, que somos seres em construção, flexíveis e mutáveis, ao adotarmos uma concepção de self narrativo, impermanente, que contraria a visão precedente de um selfúnico, essencialista e inflexível.

Para refletir sobre essa proposta apresento a seguir uma breve narrativa sobre a cliente, fazendo referência a alguns aspectos precedentes do processo terapêutico até a sessão eleita e recortada para a produção deste artigo.

\section{A HISTÓRIA DE MALU: UMA VERSÃO DEPRECIATIVA RESTAURADA POR VOZES APRECIATIVAS}

Malu é uma mulher de trinta e cinco anos, psicóloga, psicoterapeuta, separada há três anos, desde que iniciou a terapia, com um filho de quatro anos que mora com ela. Com relação à sua família de origem, tem um irmão três anos mais novo, pais separados, uma mãe com problemas psiquiátricos e um pai provedor, poderoso, com quem sempre estabeleceu uma relação de dependência econômica que, segundo relatos dela, dificultou sua entrada na adultez. Chega a afirmar que "nunca deixei de ser filha para ser esposa e mãe, sempre me senti instável profissionalmente, pouco acreditava em mim, não precisava me manter, pois desde sempre contei com o apoio financeiro do meu pai". Grande parte de seu percurso terapêutico transcorreu por um trabalho de diferenciação de self, pela busca de autonomia e a conquista de sua adultez, associada a um período de elaboração de seu processo de separação.

Enquanto profissional, Malu sempre esteve envolvida em cursos de aprimoramento profissional que não chegavam a conferir-lhe uma autoestima elevada, nem a obter uma imagem confiante e segura de si. Considerava- 
-se sempre uma pessoa muito influenciável, insegura, sem objetivos precisos na vida, com alguns momentos depressivos e dificuldades na vinculação com outros homens. Na sessão eleita para análise, se descreve "meio perdida", afastada de sua rede social e com uma imagem muito depreciativa de si. Foi neste contexto de vida dela que, baseada na visão construcionista de self narrativo, fluido e em construção, iniciamos uma conversação terapêutica que incluiu personagens significativos de sua vida que puderam ampliar sua versão de si mesma, dando novos sentidos para sua existência.

Malu começa a sessão contando a seguinte cena:

Estava sentada em uma esteira na praia, olhando o horizonte e o mar era encharcado por um vazio inesgotável e inexplicável, me dei conta das minhas lacunas a serem preenchidas... percebi que o futuro estava obscuro e um tanto indefinido. Uma necessidade arrebatadora de reconhecer quem sou me inunda e, nenhuma resposta simples ou reconfortante surge, o que parece evidenciar a necessidade de que eu mergulhe e escave mais em mim mesma.

Malu trouxe essa cena relacionada à virada do ano de 2017. Imediatamente imaginei que seria útil recorrer a outras pessoas significativas de sua vida que pudessem compor uma visão mais promissora sobre ela e fiz a seguinte pergunta: pensando no seu momento presente e na dificuldade de você se reconhecer identitariamente com as características que melhor te definem, a quem podemos recorrer enquanto olhar legitimador e apreciativo de sua existência?

Ela me responde que fez parte de um grupo de nove mulheres na faculdade, todas ligadas entre si, algumas mais próximas do que outras, que sempre tiveram um olhar especial sobre ela. Pedi que ela elegesse três delas como olhares que ajudassem a compô-la, a recuperar alguma dimensão esquecida de si, devido ao desejo constante de satisfazer às expectativas dos outros.

Assim, Malu prosseguiu:

A primeira de minhas amigas é a que mais fortemente me vem em mente, porque sempre resgatou em $\mathrm{mim}$ uma profundidade da qual sempre temi e, por esta razão, costumava me afastar. Ela nunca me deixou escapar em quaisquer de minhas tentativas rasas para me manter na superfície. Agora, pensando, me vem em mente uma cena que vivemos na casa dessa amiga: estávamos em uma piscina de sua casa que tinha ligação direta com a sauna e passamos horas a fio conversando nessa piscina, transitando e mergulhando dela para a sauna. Ela sempre ressaltava o quanto nossas conversas traziam uma profundíssima intimidade peculiar, jamais experimentada com qualquer outra amiga... era comigo que as conversas emergiam de uma cumplicidade nunca dantes experienciada. De repente, a água fria da piscina era aquecida pela sauna. Tenho a sensação que essas temperaturas sempre oscilam em minha vida. A frieza de me definir através de minha versão saturada, de minha própria descrição empobrecida de existência, era aquecida pelo afeto e pela profundidade dos novos significados que emergiam, com a leveza que extraíamos de nossas conversas. Recebendo o calor afetuoso dessa amiga, me permitia ser autêntica, verdadeira e não temia qualquer profundidade, mergulhava com as garantias do colo aquecido que sempre recebi dela. 
Seguimos a sessão com a mesma consigna: me retrate uma cena com uma amiga de forte influência em sua vida, alguém que te vê diferentemente de como você tem se descrito ultimamente.

A segunda amiga traz a marca da aceitação incondicional de minha inteireza, ela nunca permitiu que eu fosse definida por um único recorte de minha existência. Eu costumava dizer que minha vida era como uma série de TV, feita de muitos capítulos, e essa amiga era testemunha de todo o seriado, não se permitia me ver sobre o ângulo de um único episódio. Ser vista sob esta perspectiva que incorporava as diferentes dimensões do meu ser me "curava" de antigas feridas, onde fui denegrida, preconceituosamente, pelo olhar recriminador do outro. Além de me favorecer uma imagem de mim mais completa, minha amiga não passava a mão por minha cabeça, era crítica com o que me cabia revisar, sem que eu me sentisse abandonada na minha necessidade de ser cuidada.

E, por fim, Malu relatou:

A terceira e última delas que quero trazer ressaltava o meu humor, a minha autenticidade, pois ela mesma não se deixava vencer pelos olhares críticos de outrem, me convidando a usar minha ludicidade, meu humor, minha alegria e meu despojamento, sem me deixar restringir às possiveis críticas alheias. Quando eu ficava diante de sua transparência $e$ autenticidade, sem tirar nem por, me permitia, cada vez mais, ser eu mesma, de uma maneira única, original e singular, me despedindo de um hábito incômodo e inútil que me acompanhou em grande parte de minha existência, a mania que me perseguia de querer agradar a terceiros.
Finalizamos a sessão com Malu demonstrando surpresa e comoção com a rota que percorremos, com as memórias resgatadas de cenas com suas amigas que permitiram inúmeras reflexões a respeito de seu isolamento social, de sua baixa autoestima e perda de espontaneidade, afirmando estar começando a nomear sentimentos e sensações que, por muito tempo, permaneceram confusos, indefinidos e mal elaborados.

\section{CONSIDERAÇÕES CONSTRUCIONISTAS, COLABORATIVAS, NARRATIVAS E APRECIATIVAS DA HISTÓRIA DE MALU}

Os recortes acima expostos fizeram parte de conversações transformadoras entre mim e a cliente que funcionaram como um disparador para que novos significados viessem à tona dando margem a uma infinidade de reflexões. Constituíamos um encontro verdadeiro de interlocução dialógica generativa que refletia uma multiplicidade de novas oportunidades à sua vida. Imersa em princípios terapêuticos condizentes com a pós-modernidade, revisitei algumas posturas clínicas e teorias que me permitiram estar com Malu, assumindo um clima de horizontalidade, de escuta respeitosa que validasse as diferentes maneiras com que se definia e era definida pelos outros.

Nas inúmeras sessões individuais que tivemos durante um ano e meio, construímos uma atmosfera dialógica propícia à desconstrução das narrativas que reificavam posições estáticas, até então sustentadas por ela, que restringiam seu senso identitário, obscurecendo suas habilidades e seus recursos. O clima emocional que nos permeava era de responsabilidade compartilhada, 
construção conjunta de novos significados que passaram a fazer mais sentido para a cliente, permitindo a abertura para novas perspectivas futuras.

Perpassamos muitos relatos fortes de sua vida que pude testemunhar. O recorte de sessão eleito e transposto neste artigo segue na direção de uma restauração identitária constituída pelo olhar de pessoas significativas da vida dela. Pautada em um dos pressupostos do Construcionismo Social de que a nossa identidade é composta pelo olhar do outro e tecida pelos relacionamentos significativos de nossas vidas, a identidade de Malu era construída e reconstruída a partir de nossas trocas dialógicas que permitiram que ela recuperasse cenas vividas com suas amigas e pudéssemos dar significados adversos a esses relacionamentos e à imagem que, até então, ela sustentava de si. Uma vez que somos seres constituídos em relação, a versão saturada e denegrida que Malu carregava foi, aos poucos, sendo substituída pelos olhares mais positivos de suas amigas. A autoria individual cedia espaço para uma autoria múltipla através de nossa ação conjunta (Shotter, 1993).

Como terapeuta fui deixando que Malu acontecesse em mim. Deixar que o outro aconteça em você é uma expressão utilizada por John Shotter (1993), denominada outreidade. Segundo o autor, a premissa subjacente é de que, enquanto terapeuta, nunca conseguimos alcançar exatamente o significado daquilo que escutamos. $\mathrm{O}$ nosso esforço é aproximativo com relação àquilo que o cliente diz pois, ao assumirmos uma postura de estar com (withness), tentamos nos apropriar ao máximo do significado que o outro atribui ao seu relato. Por exemplo, na conversação estabelecida com Malu apareceu em duas de suas amigas a importância de ela manter sua espontaneidade e abandonar o hábito de querer agradar aos outros. Quando nos referíamos à temperatura fria da piscina e quente da sauna, fomos conjuntamente construindo analogias sobre diferentes momentos de sua vida - quando ela sentia que estava perdendo sua espontaneidade, se distanciava de seus propósitos em função da necessidade frequente de querer agradar ao outro. Essa era a sua versão fria, a temperatura que representava a sensação de estar distante de sua própria essência, o que lhe gerava uma sensação de vazio, de "despersonalização" (sic), sem metas e esperanças de futuro. Contrariamente, a sensação da sauna era de um calor aconchegante que lhe permitia reconectar-se à sua essência, encontrar razões pessoais para sua existência, de se credibilizar a partir das valorizações e legitimações escutadas das amigas. Esse "aquecimento" afetivo proveniente dos seus vínculos amistosos reverberava uma imagem de Malu mais confiante, empoderada, espontânea e, consequentemente, com perspectivas otimistas de futuro.

Até a presente sessão Malu passava por um momento crítico e frágil de sua autoconfiança, sustentava uma imagem apequenada de si, sujeita à revisão dos olhares apreciativos de suas verdadeiras amigas, amigas que fizeram parte de sua rota de vida, testemunhas de outros momentos de seu passado em que se sentia mais segura e competente. O trabalho terapêutico foi de resgate de uma imagem mais forte e determinada de seu repertório "esquecido", que trouxesse narrativas passadas de uma Malu diferente de agora, mais orgulhosa de si. O significado que ela se dava não podia pertencer unicamente à sua mente individual, mas, também, era produto dos diálogos que estabelecíamos enquanto interlocutoras (Gergen \& Warhus, 2001). 
Trazer à tona as memórias dessas amigas que representavam modelos para a cliente e resgatavam emoções positivas com as quais ela se reconectava - tais como alegria, humor, acolhimento, afeto, autenticidade e inteireza - teve um poder transformador que expandiu suas possibilidades, direcionando pensamentos e atitudes, antídotos contra uma imagem empobrecida que ela carregava de si - o princípio positivo proposto pela investigação apreciativa ancorava as minhas investigações (Cooperrider \& Whitney, 2005). Somadas a isso, as práticas narrativas de re-associação resgataram os olhares legitimadores de suas amigas, fazendo-a reconhecer a importância dessas pessoas na sua construção identitária, já que, através delas e dos diálogos que construímos, a cliente recupera sua espontaneidade perdida, sua coragem em se mostrar mais, mesmo correndo o risco de ser criticada e denegrida como havia sido em outras circunstâncias de vida pois, quando se remeteu ao quanto era reconhecida pelas três amigas, se sentiu fortalecida para se assumir mais integralmente, inclusive por ter experienciado com elas ser criticada construtivamente, sempre na direção de se tornar alguém ainda melhor.

Quando participamos de um diálogo cuja tônica é mais voltada para um discurso problemático e disfuncional das interações humanas, a realidade que surge desse diálogo é mais permeada por problemas e disfunções. Quando investigamos o que está funcionando e o que as pessoas valorizam sobre aquilo que fazem, novas realidades cheias de recursos e possibilidades são produzidas. Utilizando as ideias da investigação apreciativa de que as relações humanas são permeadas de potencialidades, sustentei um diálogo e uma linguagem que enalteciam as experiências positivas do passado da cliente que ofertavam novas realidades, valorizando diferentes versões que surgiam a respeito de Malu.

Não podia restringir Malu à visão pessimista daquele momento. Ao escavar novas histórias de seu repertório pessoal, sabia que novas realidades emergiriam, favorecendo uma multiplicidade de opções para ela. Quando, finalmente, ela relata experiências de sua maternidade, de algumas dificuldades enfrentadas com um diagnóstico difícil de seu filho, somadas a outros relatos positivos de sua vida profissional, podemos, juntas, re-significar parte do seu passado e, também, estabelecer novas projeções futuras. Novamente me reportei às práticas narrativas de re-autoria quando densifiquei a história fina, compilando experiências positivas da vida de Malu que, juntas, pudessem ser fortes o suficiente para combater sua versão dominante, enfraquecida e opressora. A pergunta disparadora para chegar a eventos extraordinários de sua maternidade foi: Em que momento de sua vida você se reconheceu diferente e mais forte, demonstrando uma versão de si que estava "apagada" ou esquecida? Malu disparou em um relato de sua maternidade, desde o nascimento de seu filho e do quão só se sentiu, porque sua mãe não teve condições psicológicas para auxiliá-la da forma como esperava até, principalmente, quando precisou encarar a realidade frente a médicos de que seu filho era especial, apresentava uma psicopatologia que requereria de Malu muito esforço, dedicação e cuidados especiais. Embora sozinha e desesperada, foi o momento onde ela se reconheceu mais forte e competente para defender a "cria"; seus receios e fantasmas se apequenaram diante da potência de seus instintos maternos. 
Interessada em recuperar outros eventos importantes de um passado remoto que conectassem Malu a uma imagem mais positiva de si mesma que fosse somada às cenas relacionadas à sua maternidade, fui escavando narrativas referentes a contextos mais positivos. Algumas perguntas relevantes que utilizei em sessão foram:

Que outras cenas de sua vida, além dessas com seu filho, podem ser relembradas como fontes de orgulho e satisfação de sua vida? Quem eram as pessoas presentes nessas cenas? Que efeitos teve para você resgatar as histórias passadas com suas amigas e recuperar o olhar de cada uma delas sobre você? Que fatores favoreceram você alcançar uma imagem mais apreciativa de si mesma? Se imagine daqui há um ano, em um cenário onde todos os seus desejos possam ser realizados; como é esse cenário? O que mudou? O que você precisou fazer para isso acontecer? O que as demais pessoas envolvidas precisaram fazer para isso acontecer? Quais são as qualidades que você mais admira em você?

O anel autorreflexivo temporal presente, passado e futuro - incluía o resgate de narrativas passadas, ressignificando-as no tempo presente e projetando, assim, um futuro diferente, nos mantendo nessa incursão temporal que privilegiou os novos significados que emergiam no presente, favorecendo uma dimensão futura que pudesse estar relacionada a um ideal mais satisfatório na direção de desejos e sonhos a serem alcançados. O processo terapêutico foi demarcado por momentos marcantes, ressaltados por elementos novos que surgiam mediante uma postura colaborativa e uma investigação narrati- va e apreciativa de uma nova história que estava sendo escrita.

Considerando, então, que as histórias não são fixas e podem estar sujeitas a transformações constantes através do contato com um interlocutor (que pode ser, inclusive, nós mesmos), elas nunca são apenas relembradas, mas, inclusive, re-significadas. Assim, nossos insights deixam de ser verdades fixas e passam a ter um status temporário que "traduz" um dado momento de nossa existência. Quanto mais excursionávamos em nossas conversações terapêuticas, mais linguajávamos, e novos significados emergiam das narrativas da cliente, em um fluxo contínuo de onde brotavam oportunidades diversificadas.

Recuperar parte de nossas habilidades perdidas e trazer à tona competências ofuscadas pode fazer parte de um processo terapêutico pautado nas práticas narrativas de re-autoria. Como terapeuta, eu garimpava histórias alternativas de Malu com suas amigas de sua vida profissional e de sua experiência como mãe que se contrapunham à versão saturada que ela carregava de si e, aos poucos, uma história alternativa, mais densa e sólida, saltava aos nossos olhos. Quanto mais adentrava essas narrativas, mais me deparava com recursos extraordinários que não condiziam com sua versão saturada.

Nossas narrativas de nós mesmos e sobre os outros são narrativas "parciais" daquilo que vivenciamos, e a proposta das práticas narrativas é, justamente, propiciar ao cliente o acesso a eventos únicos que ele mesmo possa ter estocado e omitido de sua consciência, que contrariem as versões dominantes que os constituem, muitas vezes apresentando uma versão dele próprio que o incomoda e o infelicita. Sem me deter à sua história dominante, fui escavando histórias subordi- 
nadas alternativas que permitissem à Malu adentrar outros territórios de sua identidade, explorando recursos, habilidades e capacidades até então ocultas e adormecidas para ela.

Malu se definia como inconsistente, rasa e superficial, alguém que não se apropriava da própria vida. Porém, essa visão saturada de si começava a apresentar inconsistências e contradições, lacunas que, cuidadosamente, foram preenchidas durante o processo terapêutico, principalmente em nossos diálogos à respeito de sua prática profissional como terapeuta, de como os cursos que realizava, seus estudos e todo o seu investimento eram notórios nas mudanças relativas à sua segurança e seu empoderamento profissional. Ser reconhecida como uma boa terapeuta passou a ser uma conquista celebrada e internalizada por ela, onde cada novo atendimento que fazia significava a oportunidade e a realização de se aprimorar e enxergar com admiração os seus esforços, além de obter legitimidade pelos próprios clientes.

Recuperar uma imagem mais competente de si através do olhar de suas amigas nos permitiu conversações que incluíam outra prática narrativa denominada re-associação (re-membering). Esta prática utilizada por Michael White sofreu influência direta dos trabalhos desenvolvidos pela antropóloga Bárbara Meyerhoff, com grupos de minoria, chegando a considerar a importância do termo re-membering (re-membrar, re-associar), ressaltando o significado de recuperarmos pessoas importantes em algum momento de nossas histórias de vida que permaneceram "apagadas".

Ao trazer à tona algumas das melhores amigas de Malu através da prática narrativa de re-associação, que ressalta figuras importantes que foram apagadas da memória do cliente, ela pôde se remeter à importância de cada uma delas na construção de sua identidade e, consequentemente, como passaram a influenciar na forma como ela se percebia, compreendendo, conjuntamente à cliente, que sua identidade podia ser moldada diferentemente com os acréscimos tecidos por esses relacionamentos.

As três amigas apontadas pela cliente, resgatadas de seu clube da vida (White, 2012; White \& Epston, 1990), são figuras recuperadas de seu acervo afetivo que representam o retrato refletido do melhor dela, permitindo que cada uma delas recompusesse sua identidade a partir de momentos extraordinários relembrados e ressignificados que fizeram parte de narrativas passadas (Mofarrej, Costa \& Pacheco, 2017).

Rememorá-las na sessão trouxe à tona valores, propósitos e percepções há muito tempo esquecidos que deram um novo sentido à vida de Malu. Alguns de seus atributos pessoais, com os quais não se conectava há tempos, foram garimpados e restituídos à sua identidade. Felizmente o seu self não mais permanecia enrijecido numa única versão.

\section{PERSPECTIVAS FUTURAS NA VIDA DE MALU}

As sessões subsequentes foram encharcadas de conteúdos explorados precedentemente. Revisitar sua postura de vida, reencontrar novos amigos que compuseram e somaram aos anteriores uma imagem mais repleta e satisfatória de si mesma fez Malu refletir sobre seus relacionamentos, inclusive revisitar seu percurso afetivo-sexual. Quando a questionei sobre os efeitos de nosso encontro onde exploramos o olhar de suas três amigas sobre ela, pude me surpreender com sua resposta: 
Houve um efeito corporal pós sessão, onde passei a questionar a imagem que carregava nos últimos anos, questionando e restaurando, aos poucos, uma imagem mais satisfeita e orgulhosa de mim a partir do olhar de minhas amigas. Me senti descomprimida, com uma sensação de expansão e amplitude, ganhando espaço. Cheguei a transferir esses pensamentos e sensações para o meu corpo e comecei a fazer movimentos com minhas mãos semelhantes a movimentos de uma borboleta.

Ao relatar seus movimentos de borboleta, estávamos diante do que Shotter denomina de momentos marcantes, onde se abrem novos caminhos e perspectivas para a vida do cliente, que passa a responder ao entorno diferentemente. São momentos que se constroem do inesperado; uma forma poética de expressar novas compreensões daquilo já vivido, encontrando respostas corporais às falas dos interlocutores, ao mesmo tempo que permitem ao cliente seguir adiante (Anderson, 1996 apud Grandesso, 2018; Shotter \& Katz, 1999). Assim Malu completou:

Fui encontrando coragem para alçar alguns voos, sair do meu isolamento e buscar amigos "esquecidos". Essa descompressão possibilitou reencontros com outras pessoas do passado, que sempre traziam alguma imagem de mim 'apagada'. Quanto mais encontros desses eu participava, mais repleta e inteira me sentia. Fui ressignificando uma característica muito marcante de meu passado, a sensibilidade, deixando de associá-la à fragilidade.

E continuou:
O que mais ressaltava em mim mesma era a capacidade de estar disponível para o outro. Antes, disponibilidade era sinônimo de facilidade com os homens, estar em uma condição vulnerável frente ao masculino que autorizava que abusassem de mim. Mas quando transpus essa característica para o meu campo profissional, minha profissão de terapeuta, estar disponível para os meus clientes é uma das minhas maiores virtudes, o que me faz ser boa profissional, reconhecida. Ao me revisar, começo a redescobrir que gosto de minha simplicidade, do meu senso de justiça e de minha espontaneidade. Aos poucos vou compondo um mosaico daquilo que sou, que sinto e gosto em mim. A frágil e débil identidade de outrora cede espaço para uma nova mulher que surgia de dentro de mim.

Quando finalmente encontrei espaço para introduzir a dimensão futura em seu relato, Malu disse temer que eu fizesse esta tão esperada pergunta, embora não se desconcertasse em me responder. Disse que se via daí a um ano consolidando cada vez mais o espaço terapêutico que havia recém inaugurado em sociedade com uma colega, que as sessões durante esse ano e meio de percurso terapêutico, principalmente aquelas onde rememorou cenas com sua amigas, ajudaram muito em se revisar identitariamente, possibilitando que ela repensasse certas posturas na vida, inclusive em seus próximos relacionamentos com os homens, pois se sentia mais consolidada, segura e disposta a assumir um compromisso. Deixei uma reflexão para a sessão posterior - que nos levaria à exploração de sua disponibilidade com o masculino. Esse era o novo tema que emergia para nossas próximas conversações. 


\section{CONSIDERAÇÕES FINAIS}

Quando "abrimos os nossos olhos e encaramos nossa cegueira" (McNamee\& Gergen, 1998), somos privilegiados por um olhar mais genuíno e menos condicionado pela supremacia de crenças dominantes; deixamos que o outro aconteça em nós (Shotter, 1993).

O contexto dialógico da psicoterapia se desenvolve ao redor de um dilema a ser dissolvido mediante a fusão de horizontes entre os interlocutores - "mergulhar na piscina" com Malu nos envolveu em uma atmosfera quente da sauna, protegida pelo afeto que lhe garantiu uma entrega verdadeira $\mathrm{e}$ transformadora, apenas possível pelo encontro entre nós.

Inúmeros foram os momentos marcantes que vivenciamos e testemunhamos. Recompor lacunas de uma identidade frágil através de olhares legitimadores permitiu à Malu se recompor e se restaurar de antigas feridas, de posturas precedentes que obstruíam suas possibilidades existenciais. Estar comprometida com uma única história de self e identificá-la como a única verdadeira era limitar terrivelmente as inúmeras versões de si mesma.

A reconstrução de sua narrativa abriu novos cursos e possibilidades de vida que permaneciam restritas em um recorte empobrecido. Ressignificar suas histórias ampliou suas perspectivas, suas ações e experiências, renovando o seu repertório, mesmo sabendo que suas reflexões são fruto de momentos marcantes e transformadores que podem se estender ou não para além da terapia, caso Malu reflita sobre sua postura nos futuros relacionamentos e na forma como se percebe. Imersa em diferentes abordagens pós-modernas, pude transitar entre práticas narrativas, conceitos e pressupostos construcionistas e oferecer uma investigação apreciativa que favoreceu a Malu estar consigo mesma e com os outros diferentemente.

Quebrando antigos preceitos, imagens imaculadas e enrijecidas que obstruíam seus movimentos libertadores, ela renovava seu repertório com olhares múltiplos, internalizados de pessoas significativas de sua vida. Em cada olhar ela se via mais e melhor, deparava-se com um espelho cuja imagem refletida a dignificava. Ao se remeter a cenas vivenciadas internalizadas com suas amigas que ressaltavam suas virtudes e competências, Malu ressurgiu mais empoderada. Um novelo de histórias foi desatado por nossas conversações, nos surpreendendo pela poética social.

Iluminadas por histórias subordinadas e pelos novos significados que brotavam de nossos encontros, essa nova versão de Malu encarnou a esperança de passos fortes em direção a um futuro mais consciente de suas fragilidades, seus méritos e de um acervo afetivo que a direcione para possíveis novas conquistas. Compartilhamos momentos marcantes, transformadores de sua identidade, uma vez sustentadas pela noção de self dialógico e relacional. Em nossas trocas dialógicas atuamos com uma multiplicidade de vozes que habitavam nela, vozes internalizadas de suas amigas que permitiram mudanças significativas no contexto local do qual participamos. Esperemos que essas transformações se façam presentes em outros cenários e relacionamentos, mesmo que não possamos garantir a extensão do alcance dessas transformações. 


\section{REFERERÊNCIAS}

Anderson, H. (2011). Conversação, linguagem e possibilidades: um enfoque pós-moderno da terapia. São Paulo: Rocca.

Anderson, H. (2017). A Postura Filosófica: o coração e a alma da prática colaborativa. In M. Grandesso (Org.),Práticas colaborativas e dialógicas em distintos contextos: um diálogo entre teorias e práticas (pp. 21-34). São Paulo: CRV.

Cooperrider, D. L. \& Whitney, D. (2005). Investigação apreciativa: uma abordagem positiva para a gestão de mudanças (N. Freire, Trad.). Rio de Janeiro: Qualitymark.

Galvão, A. V. \& Guimarães, N. (2014). Infância segregada, infância renarrada. In N. Guimarães (Org.),Autoridade e autonomia em tempos líquidos: a teoria sistêmica na contemporaneidade (pp.163179). Belo Horizonte: Ophicina de Arte \& Prosa.

Gergen, K. (2016). El ser relacional: más allá del yo y de la comunidad. Bilbao, ESP: Desclée de Brouwer.

Gergen, K. J. (2017). Construção social e comunicação terapêutica. In M. Grandesso (Org.), Práticas colaborativas e dialógicas em distintos contextos: um diálogo entre teorias e práticas. São Paulo: CRV, p. 107-142.

Gergen, K. J. (2018). Ética relacional na prática terapêutica. In M. Grandesso (Org.),Colaboração e diálogo: aportes teóricos e possibilidades práticas (pp. 189-200). Curitiba: CRV.

Gergen, K. J. \& Warhus, L. (2001). La terapia como una construccion social dimensiones, deliberaciones, y divergencias.Asociación Sistémica de Buenos Aires Sistemas Familiares, 17(1), 11-27.
Gergen, K. J. \& Gergen, M. (2010). O construcionismo social: um convite ao diálogo. Rio de Janeiro: Instituto Noos.

Grandesso, M. (2000). Sobre a reconstrução do significado: uma análise epistemológica e hermenêutica da prática clínica. São Paulo: Casa do Psicólogo.

Grandesso, M. (2018). A poética da conversação terapêutica. InColaboração e diálogo: aportes teóricos e possibilidades práticas (pp. 149166).Curitiba: CRV.

Guanaes, C. (2006). A construção da mudança em terapia de grupo: um enfoque construcionista social. São Paulo: Vetor.

Lax, W. (1998). O pensamento pós moderno na prática clínica. InS. McNamee \& K. Gergen (Orgs.), A terapia como construção social (pp. 86-105). Porto Alegre: Artes Médicas.

McNamee, S. (2018). Profissionais como pessoas: encontros dialógicos para transformação. In $\mathrm{M}$. Grandesso (Org.), Colaboração e diálogo: aportes teóricos e possibilidades práticas.(pp. 75-95). Curitiba: CRV.

McNamee, S. \& Gergen, K. (1998). A terapia como construção social. Porto Alegre: Artes Médicas.

Mofarrej, G., Costa, M. F., \& Pacheco, V. (2017). A contribuição da entrevista apreciativa em um processo terapêutico colaborativo. In $\mathrm{M}$. Grandesso (Org.), Práticas colaborativas e dialógicas em distintos contextos: um diálogo entre teorias e práticas(pp. 201-224). São Paulo: CRV.

Palma, F. G. (2008).Terapia narrativa: ideias sistêmicas. Caderno do CEFAI, $V(5)$.

Rasera, M. \& Guanaes, C. (2010). Momentos marcantes na construção 

Psicologia: Teoria e Pesquisa, 26(2), 315-322.

Shotter, J. (1993). Conversational realities: constructing life throughh language. London: Sage.

White, M. (2012). Mapas da Prática Narrativa. Porto Alegre: Pacartes.

White, M. \& Epston, D. (1990). Narrative Means to Therapeutic Ends. New York: Norton.

\section{NINA VASCONCELOS GUIMARÃES}

E psicóloga, psicoterapeuta sistêmica de indivíduos, casais e famílias, mestra em Família na Sociedade Contemporânea (UcSal-BA). Diretora do Instituto Humanitas de Pesquisa e Intervenção em Sistemas Humanos (Salvador/BA). Membro associado do THE TAOS INSTITUTE (http://www. taosinstitute.net). Salvador, Brasil.

E-mail: ninavg40@gmail.com 